\title{
Economía de los objetos. Los objetos como instancias de afectividad y valor económico en la constitución de la sociedad economizada ${ }^{1}$
}

\author{
Víctor Manuel Hernández Ramírez \\ Universitat Autònoma de Barcelona \\ herramv@gmail.com
}

Director/a: Félix Vázquez Sixto

Como se puede constatar, el trabajo aborda la emergencia de los objetos como algo económico, es decir en su valor de cambio e indaga por el procedimiento que hace posible dicha economización. Es un texto con vicisitudes de las que intenta dar cuenta el texto que sigue, que reflexiona sobre una indagación que pretende responder al estatus de los objetos y su relación con nosotros, en una sociedad economizada.

La explotación capitalista se realizó sin que su teoría hubiese sido jamás formulada directamente en un discurso. En efecto esta teoría se reveló posteriormente por un discurso analítico: discurso histórico o económico. Ahora bien, ¿los procesos históricos de explotación se ejercieron o no en el interior de un discurso? Se ejercieron sobre la vida de las personas, sus cuerpos, sus horarios de trabajo, su vida y su muerte. (Foucault, La verdad y las formas jurídicas, 1978, p. 162).

Con éste fragmento de Foucault, quiero explicitar que el origen del presente trabajo se sitúa en una aprehensión que, me parece, ha acompañado el proceso de constitución de la sociedad (pos) moderna. Me refiero una condición de ansiedad que suscita el despliegue y funcionamiento de la economía capitalista en tanto es algo que se ejerce sobre la vida, los cuerpos, los horarios de trabajo y la muerte de la gente, como dice Foucault; es decir, que la sociedad como algo economizado no consiste en una mera determinación, no es algo que solamente se configura en sus formas institucionales y estructuras, sino que aparece como un efecto con efecto, como aquello que configura un orden y una fuerza de lo económico con la fatiga del trabajo, las decepciones cotidianas, los deseos que energizan el esfuerzo, los ritmos incesantes, el dolor y la explotación dosificados, las ilusiones que son efímeras pero que renacen.

Son las condiciones de una sociedad en la cual los afanes cotidianos, las formas ordinarias de la aprehensividad y la tensión, funcionan conjuntamente con las prácticas económicas de producción, de consumo, de intercambio, de valoración mediada por el precio en dinero y salario.

Se trata, en fin, de un rasgo paradójico de la forma que tiene lo económico, a saber que lo económico sólo tiene una imagen que se percibe como coherente si toma una forma fría y calculadora y se la mira como el mundo de la intercambiabilidad y el mercado o toma la forma cálida y subjetiva de los intereses y vivencias de quienes operan como agentes sujetados dentro del mundo economizado. Así

1 El trabajo de investigación, en su versión completa, se puede descargar en http://www.molekulab.net/linux/Trabajo Investigacion Economia de los objetos 2006.pdf 
pues, es un rasgo que opera al modo de aquellas figuras clásicas de la Gestalt, en las cuales no se pueden ver las dos imágenes al mismo tiempo, sólo puede verse una de las dos formas, aún sabiendo que la otra forma está allí y es posible de verse también, pero sólo renunciado a la una. En el mundo de la economía, la intensidad palpitante del quehacer y padecer humanos se muestra, aparentemente, sólo en la extensividad de una estructura que no admite afectos sino que se despliega y opera por sí y desde sí misma. Lo que, al parecer, no se puede ver de modo sinóptico, es de qué manera las prácticas económicas son correlativas tanto a esa dimensión cualitativa e intensa de la afectividad como a la dimensión cuantitativa y extensa de su estructuración como mercado.

Mi proyecto de investigación se ubica en esa aprehensividad e inquietud, así como en esa especie de doble naturaleza de lo económico, que toma la apariencia formal de la racionalidad eficiente y, sin embargo, se hunde o penetra prácticas sociales en las cuales hay objetos. Los objetos son tomados, en primer lugar, como instancias, lo que resulta de la acción de instar e instar es (según en Diccionario de la Real Academia) la repetición con ahínco de una petición o una súplica, es también la impugnación de un argumento y por tanto se asocia con la polémica (sobre todo en el ámbito jurídico) y es también la acción que urge o incita la pronta ejecución de algo; una instancia es también un memorial o una solicitud, así como un ámbito donde un proceso se detiene y tienen lugar ciertas operaciones jurídicas. En tanto instancias, los objetos se consideran una forma de materialidad que condensa acciones, el trazo y la densidad de una acción recíproca y vectorial, es decir que los objetos son la síntesis o el anudamiento de unas acciones que se han estructurado de una cierta manera y que posibilitan unas determinadas acciones sucesivas. Pero no es que haya algo que repose en el objeto, sino que allí hay algo operativo; vale decir que para los objetos, su modo de ser instancia tiene que ver con su expansión (puesto que ocupan y usan el espacio) y su operación o funcionamiento. La sospecha fundamental de ésta investigación es que los objetos son instancias privilegiadas para pensar las formas de economización de la sociedad, en tanto podemos tomar una especie de "unidad de análisis" que sería el ámbito del objeto, considerado no como cosa sino como instancia, es decir como una materialización de procesos que tienen carácter local y que operan más allá de los contornos del objeto mismo, también pueden ser instancias privilegiadas para analizar el funcionamiento de lo económico en tanto se entiende a los objetos como entidades semiabiertas y a la vez clausuradas. Me explico, el modo de operar de los objetos, en tanto se relacionan en procesos recíprocos de valorización (Simmel, 1900, 1958) indica que en esa relación de objetos acontecen procedimientos de vivo interés que tienen que ver con el proceso de valorización: ¿qué hace deseable un objeto, además del costo de sacrificio en la relación de valoración recíproca y de intercambio? ¿qué le da iterabilidad, es decir que le hace un objeto disponible y accesible a muchos otros? ¿qué lo economiza, es decir que le hace traducible a un valor cuantitativo, reductible a un precio y sujeto a variaciones en la circulación de mercancías y valores? Pero un objeto también está clausurado, puesto que su iterabilidad tiene una orientación y el objeto es útil para ciertas cosas y con ello determina situaciones y, sobre todo, el objeto es mudo, tiene opacidad, lo cual suscita fascinación pero también indiferencia, pues prueba de ello es que los objetos pueden ocupar el lugar de lo sagrado y el lugar de lo insignificante.

Lo que esta investigación pretende es analizar de qué manera los objetos operan como instancias de afectividad y valor económico. Aquí la hipótesis se ha configurado con el concepto de valor que desarrolla Simmel con respecto al modo que tienen los objetos para funcionar y potenciarse como cosas de valor económico: se trata de una noción relacional, puesto que para Simmel, me parece, el valor es una estructura de acción recíproca, de acción constituida únicamente en una reciprocidad compleja. La noción parece ser de carácter psicológico, aún cuando Simmel siempre se mueve 
transdisciplinarmente, pero esto parece claro en tanto Simmel considera importante que haya un deseo y una dificultad o sacrificio que se ponen en relación entre dos objetos que operan en el campo del valor de cambio; en dicha reciprocidad también se ponen en tensión y se juegan mutuamente la disponibilidad del objeto (lo cual se asocia con su producción) y su escasez (lo cual se asocia con su potencial de singularización). Así, para la noción de valor es absolutamente y únicamente relacional entre dos objetos y no se halla afuera de la relación, y además es una noción que se coloca en la frontera de lo no económico y lo económico. Incluso, la noción misma de valor simmeliana es un a priori para la posterior explicación del dinero como objeto que media en la valoración economica de los objetos.

Como se puede advertir, podía desarrollarse una dimensión de afectividad en la noción de valor que Simmel plantea y que me parece muy útil para precisar el modo totalmente relacional que tienen los objetos para constituirse mutuamente. Esa posibilidad deriva del hecho de que la noción de Simmel es parcialmente una noción psicológica, por el papel que juega el deseo "entre" objetos. Pero me ha parecido preferible que lo afectivo no se defina por contenidos que clásicamente se asocian con las emociones o con rasgos psíquicos u operadores psíquicos, como seria viable hacer con el término "deseo". La decisión reside en que me parece necesario evitar la inoculación apresurada de alguna "psicologización" en el proceso de constitución entre lo económico y los objetos. Es un riesgo que veo plausible y que posiblemente ocurra en una diversas investigaciones de sociología y psicología social de la economía, es una posibilidad que he llamado la "racionalidad blanda" en los estudios de lo económico. Incluso se llega a advertir la operación de ésta racionalidad blanda en estudios de notable interés como las etnografías del mercado financiero o los análisis de la teoría actor-red en el campo de lo económico, en los cuales lo subjetivo sólo se describe por relaciones más complejas o como acciones en red que tienen significaciones locales y momentáneas. Se trataría de una consecuencia o efecto, posiblemente no buscado, de la producción de conocimiento sobre un practicas socioeconómicas que pueden devenir en la justificación de normas morales de los actos económicos.

Y una vez tomada la decisión de vigilar y evitar la confusión entre lo afectivo y contenidos psicológicos ¿cómo proceder? De un modo muy impreciso todavía, he sugerido que la afectividad se entienda desde la perspectiva de la forma, desde un punto de vista estético. Inicialmente me he valido de la teorización cuasi-literaria de Pablo Fernández $(2000,2004)$, pero son planteamientos insuficientes para explorar el modo de valoración económica que se ocurre con los objetos y precisar en qué sentido se dan formaciones que podemos llamar afectivas. En realidad, la economización de los objetos es lo que más radicaliza el modo de operar de los objetos como instancias no afectivas, como aquello que vincula de un modo sorprendente y, al mismo tiempo, deja afuera las personas y su subjetividad. La economía de los objetos es la objetivación que demuestra radicalmente que los objetos son parte de un ámbito con estructuras de cálculo y procedimientos burocratizados y orientados al plus valor.

Pero hay una tradición que se caracteriza por un análisis crítico sobre la materialidad y su modo de funcionar de formas en la economía en la cual nuevamente emergen cuestiones de subjetividad, pero en una dimensión política. Marx es un ejemplo clásico de esta tradición que toma la materialidad y la fracciona, la explicita, de una manera que desvela otras operaciones no económicas en lo económico; como en el famoso de ejemplo de la mesa que deviene en mercancía: la mesa es un objeto que se anima, que participa en una danza de objetos que se relacionan para constituir el mundo de la oferta y la demanda, el mundo de la lógica del mercado. Es por Marx que emerge el fenómeno paradójico de la materialidad que cobra vida y somete y configura a sujetos para su servicio, como un sistema 
auto poiético, es decir la materialidad operando dentro del capital y éste como una Matrix que se autorregula y nos sujeta. Es el efecto de la fetichización de la mercancía. Con todo, la fetichización de la mercancía es una ficción construida sobre una noción que Marx no problematiza de modo suficiente, y es la noción de valor de uso. Derrida lo indica y abre nuevamente la cuestión de una noción de valor que se contamina mutuamente entre el valor de uso y el valor de cambio de los objetos-mercancías. La consecuencia es una economía espectralizada, con objetos encantados o embrujados, con la ventaja de que se abre positivamente la discusión de lo político (como por ejemplo hace Derrida con su "mesianismo sin Mesias" o "estructura de la esperanza sin espera") pero con la dificultad de que los objetos se han contaminado aún en su valor de uso. Dicho de otra manera: parece imposible pensar objetos afuera de su economización y resulta muy complicado, por no decir desmesurado, indagar por la relación entre los objetos y lo económico.

Aquí es donde he sugerido retomar la noción filosófica de valor de Simmel. Porque su noción de valor es sólo en parte psicológica y, por otra parte, es una noción filosófica que sugiere que los objetos no acontecen como algo valorizable sino en la reciprocidad y desarrolla el valor como un antecedente conceptual del intercambio económico por medio del dinero. Es decir, que Simmel propone salirse de una determinación absoluta del valor, como en el caso de Marx es la valoración de la fuerza de trabajo (y como opera en el capital, aún como General Intellect) y sugiere que posible pensar el valor como algo que ocurre allí, localmente, que se economiza y no es económico a la vez, que hace posible esa estructura de reciprocidad entre el deseo y el costo, de accesibilidad y escasez. Por ello sugiero usar la noción de Simmel para generar una ficción de objetos que operan (todavía no) economizados y considerar plausible una estructura de acción que es a la vez virtual y real, potencial y realizada, para analizar en lo concreto, localmente, un modo de operar de los objetos "como si" fueran objetos (aún no) economizados y describir sus modos de operar socialmente, como instancias de olvido, de generación de tiempo, de técnica y de conocimientos. Reconozco que hay una especie de "petición de principio" en la argumentación, dicho como crítica a su articulación lógica, o quizá deba decir "una petición excesiva de confianza" al interlocutor de este proyecto, pero podría considerarse un ejercicio sobre ficciones de operatividad en objetos, imaginados o conceptuados como si no fueran mercancías, precisamente porque gracias a ello lo son.

En el breve planteamiento que hago de los objetos como operadores de olvido, generadores de tiempo, operadores de técnica y de conocimiento hay mucha irregularidad. No son nociones uniformemente definidas ni muy desarrolladas en tanto operadores analíticos. Por ahora sólo querría anticipar algunas posibles implicaciones: primero que los objetos conjugan estas cualidades, como por ejemplo al operr el olvido son dispositivos de memoria, pero no de cualquier modo, sino en tanto operadores de historias que han fijado hallazgos de saber práctico y lo han localizado fuera del cuerpo, en una cosa que no es más una cosa, sino un "objeto para", es decir que el objeto es un fragmento de memoria des-corporizado, por lo cual puede operar como olvido y tiene técnica y puede generar conocimiento. Otra implicación posible es que los objetos tienen incriptada una historia y una política en su cosidad y en su operatividad de olvido, técnica, temporalidad y saber. Esto implicaría que los objetos suponen un modo de imposición de lo histórico y de definiciones políticas que no son susceptibles, al menos desde los objetos mismos, de politizarse o someterse a la crítica de lo histórico. Por último, me parece que los objetos abren un problema importante con respecto a papel de agentes o como operadores de conectividad, el cual consiste en decidir si los objetos comunican y tienen un papel de signos o símbolos o sólo es así por el efecto de una discursividad de las ciencias sociales que, por razones de método o perfil teórico, les adscribe dicha función. El problema es 
importante porque tiene que ver con definir el sentido con el cual se habla de que los objetos tienen agencia u operan de ese modo en los sistemas sociales.

Pero el ejercicio ficticio, al menos en el cuerpo de mi proyecto de investigación, tiene un dejo de imposibilidad, un matiz de fracaso en la indagación. Porque es evidente la opacidad de los objetos y la enorme dificultad para analizarlos en el proceso de economización. $Y$ sobre todo, porque las formas de operación de los objetos, sea como olvido, tiempo, técnica y conocimiento, pueden considerarse formas de lo afectivo si se quiere, pero ello no explica su relación con el valor de un modo preciso y, además, porque tampoco se explica la relación entre el modo objetivo y descarnado de los objetos como mercancías y el modo subjetivo o subjetivado que conllevan los objetos como operadores de socialidad. Anoto la imposibilidad o el aparente fracaso de las indagaciones sobre los objetos pensados no economizadamente, con el fin de reconocer la envergadura de uno de los propósito del trabajo, analizar la relación entre objetos y lo económico, y también para trabajar ulteriormente sobre estos modos de operación de los objetos frente al hecho de que son instancias (previamente) economizadas. Como conclusión negativa, esto afecta el modo de trabajar con objetos en otras investigaciones e impone la necesidad de trabajar con más cuidado el umbral de lo económico y lo no económico en los objetos.

A modo de nueva indagación, orientado al mismo propósito de analizar la relación entre objetos y lo económico, sugiero ir a objetos vetustos o caducados, objetos que son no - objetos y por eso el análisis del purgatorio - usura, en la Edad Media, como objeto que se economiza y economiza la sociedad. El objeto purgatorio - usura permite pensar la emergencia de unas "condiciones de existencia", para decirlo en lenguaje de Marx, del capitalismo moderno. Me he limitado a una exploración inicial del modo en que dicho objeto emerge y opera, se constituye y responde, a una serie de problemas de su sociedad, en medio de vivas polémicas que me parecen de sumo interés para pensar esas condiciones de existencia actuales. Pero otros problemas se han dejado de lado. Uno es el problema del origen histórico del capitalismo como sistema mundo, que en una línea muy importante de investigación (Wallerstein, Dussel, estudios poscoloniales) se ubica en el siglo XVI y que señala que no es posible un sistema capitalista sin las condiciones que hace posible la colonización de América; por ello, Dussel diría que el proceso de emergencia de sistemas bancarios, contables y de comercio en la baja Edad Media, serían parte de un proceso "intrauterino" de la Europa medieval. El estudio del purgatorio como objeto que opera dentro de un proceso de economización parece, entonces, demasiado local o provincial y puede interpretarse como una argumentación que refuerza la ficción intelectual del eurocentrismo o el llamado "mito de Europa". También he dejado de lado una visión más crítica y menos dependiente de los estudios históricos a que recurro, fundamentalmente Le Goff y su perspectiva de la escuela de los Annales, la cual, como se sabe, privilegia un trabajo histórico más centrado en las prácticas sociales y en dimensiones materiales de la vida cotidiana, pero también incluye una dimensión subjetiva o psicológica con la noción de mentalidades. No obstante, hasta donde logro saber, el estudio de Le Goff sobre el purgatorio y sobre los usureros de la baja Edad Media tiene un considerable consenso en sus rasgos generales. Lo que resulta de mucho interés es la visibilidad que se logra del objeto en su emergencia y su economización. Sobre todo, permite pensar la cuestión económica con relación a una estructura de lo trascendente que tiene plena operatividad en la sociedad medieval y no se juegan con dispositivos de "negación" de dicha dimensión. Habría que pensar en qué medida, la constitución de una sociedad que opera con un referente de trascendencia por su imaginario religioso, es más apta para poner límites a prácticas económicas que tenían efectos perniciosos o para polemizar dichas prácticas. Y también habría que pensar en qué medida el capitalismo opera de modo inverso a lo que 
alguna vez Pierre Bordieu observó en la economía de las iglesias: "operan simulando que lo económico no es económico en sus prácticas religiosos". Quizá algo parecido se pueda decir de ciertos modos de operación de la sociedad capitalista.

Sin embargo, hay algo que siempre queda, mucho más concreto y simple. Los objetos. Simples en apariencia, porque son endiabladamente complejos, como dijera Marx de su mesa que también es una mercancía que se para en cuatro patas. Los objetos quedan, restan, se quedan, llevan la historia y la hacen imposible, tienen un sino político y clausuran también lo político. Es el riesgo de los objetos, como es su economización una condición innegable, puesto que los objetos operan no sólo para economizar sino como cosas ya economizadas, por eso son mercancías desde muy atrás y lo son de manera nueva en la producción incesante de cosas para el consumo. Invocar la economización de los objetos parece casi el adiós a los objetos como instancias de afecto, como vínculos no pervertidos por el vínculo comercial, pero esta parece ser la decisión que nuestra sociedad ha tomado desde mucho tiempo atrás. 